\title{
The Effectiveness of Right- vs Left-lateral Starting Position in Unsedated Diagnostic Colonoscopy with Modified-water Immersion Method: A Randomized Controlled Trial Study
}

This article was published in the following Dove Press journal:

Clinical and Experimental Gastroenterology

\author{
Putut Bayupurnama (iD \\ Neneng Ratnasari (i) \\ Fahmi Indrarti ${ }^{1}$ \\ Catharina Triwikatmani' \\ Sutanto Maduseno' \\ Siti Nurdjanah' \\ Felix W Leung ${ }^{2}$ \\ 'Division of Gastroenterology and \\ Hepatology, Department of Internal \\ Medicine, Faculty of Medicine, Universitas \\ Gadjah Mada/Dr Sardjito General \\ Hospital, Yogyakarta, Indonesia; \\ ${ }^{2}$ Sepulveda Ambulatory Care Center, \\ VAGLAHS and David Geffen School of \\ Medicine at UCLA, Los Angeles, \\ CA, USA
}

Correspondence: Putut Bayupurnama Division of Gastroenterology and Hepatology, Internal Medicine Department, Faculty of Medicine, Universitas Gadjah Mada/Dr.Sardjito Hospital, Yogyakarta, Indonesia Email pututby@yahoo.com

\begin{abstract}
Objective: A colonoscopy study in sedated patients with air insufflation showed that rightlateral starting position (RLP) improved abdominal discomfort and reduced cecal intubation time. The aim of this study was to determine if RLP vs left-lateral starting position (LLP) may produce similar results in unsedated patients examined with a modified-water immersion (m-WI) method.
\end{abstract}

Methods: Consecutive patients for diagnostic colonoscopy meeting the inclusion criteria were randomized. Patients and colonoscopist were unblinded. The m-WI method entailed suction during insertion not only for fecal debris evacuation but also to facilitate passage through difficult or angulated colonic flexures. Water was infused as needed when any difficulty was encountered during insertion. A bowel visualization scale (BVS) $(0=$ totally blurred visualization; $1=$ blurred lumen visualization; $2=$ small fecal debris with clear mucosa visualization; $3=$ clear visualization) was used to evaluate the interference of fecal debris with cecal intubation rate and time.

Results: A total of 142 patients (72 in RLP and 70 in LLP) were enrolled. The respective pain score, visual analog scale, (VAS) and cecal intubation rate were not significantly different. The cecal intubation time was nearly significantly different $(13.4 \pm 4.5 \mathrm{~min}$ vs $11.7 \pm 5.4 \mathrm{~min} ; p=0.054)$ and was significantly different in the constipation subgroup (16.0 $\pm 3.5 \mathrm{~min}$ vs $8.6 \pm 3.8 \mathrm{~min} ; p=0.001)$. The cecal intubation time based on BVS showed significant difference between RLP and LLP in Scale 2 (13.9 $\pm 4.6 \mathrm{~min}$ vs $10.3 \pm 4.2 \mathrm{~min}$; $p=0.003)$ and Scale 2 and 3 combined $(13.2 \pm 4.3 \mathrm{~min}$ vs $10.6 \pm 4.8 \mathrm{~min} ; p=0.01)$, respectively. Conclusion: RLP did not improve the pain score, and LLP showed better performance in unsedated m-WI colonoscopy patients (ClinicalTrial.gov, NCT03489824).

Keywords: unsedated colonoscopy, colonoscopy starting position, water immersion

\section{Introduction}

Abdominal discomfort is the most important factor in an unsedated colonoscopy examination. The water method for colonoscopy examination has been studied widely and evidence showed effectiveness in reducing discomfort and cecal intubation time and increasing cecal intubation rates in unsedated patients. ${ }^{1-3}$ Our previous studies showed that the water immersion method reduced the visual analog scale (VAS) score, shortened the intubation time significantly without changing cecal intubation rate. ${ }^{3}$ Previous right-lateral (RLP) vs left-lateral (LLP) starting 
position colonoscopy study in sedated patients with air insufflation colonoscopy method showed that RLP starting position improved abdominal discomfort and shortened cecal intubation time. ${ }^{4}$ We were interested to know if the RLP starting position could also maximize the water method advantages in lowering the discomfort score, shortening cecal intubation time, and achieving higher cecal intubation rates, and it would improve patient acceptance of water unsedated colonoscopy and willingness to repeat. The unsedated method has many advantages, mainly in obviating the direct (eg fees) and indirect (companion requirement after colonoscopy) cost of sedation. Studies showed that the use of water infusion rather than air insufflation improved colonoscopy performance in unsedated patients ${ }^{2,3}$ and the choice of high flow rates endoscope-connected water pump showed improvement in cannulation of rectosigmoid, discomfort score, and cecal intubation time. ${ }^{5}$ The water method, especially water exchange, also improved the adenoma detection rate. $^{6}$

\section{Patients and Methods}

This unblinded randomized controlled study was conducted in Division of Gastroenterology \& Hepatology, Department of Internal Medicine, Faculty of Medicine, Universitas Gadjah Mada/Dr Sardjito General Hospital, Yogyakarta, Indonesia. The protocol was approved by Biomedical Research Ethics Commission of the Faculty of Medicine, Universitas Gadjah Mada, Yogyakarta, Indonesia, and registered in ClinicalTrial.gov (NCT03489824). This study was conducted in accordance with the Declaration of Helsinki.

Eligible patients (based on indication) in the hospital clinics or wards were offered modified water immersion (m-WI) unsedated colonoscopy examination (Figure 1). The principal investigator (PB) explained the bowel preparation (we used sodium phosphosoda) and the study, the m-WI colonoscopy procedure, RLP or LLP of colonoscopy, the various symptoms that might be felt during the examination, the possible adverse event and medical effort to prevent it. The patients who signed the written informed consent were randomized with simple randomization. Inclusion criteria: adult $>18$ years old with the indication for colonoscopy, such as chronic diarrhea, chronic constipation, hematochezia, chronic lower abdominal pain, positive fecal occult blood test, and other change of bowel habit symptoms were enrolled. Exclusion criteria: patients who refused to participate, patients with obstructive lesions in the colon, patients with colon resection, patients who were hemodynamically unstable, and patients with severe cardiac disorders (such as acute myocardial infarction, unstable angina, malignant arrhythmia, and moderate to severe congestive heart failure). This study was conducted between February 2018 and December 2019.

Methods on the day of the exam, enrolled patients were sent to the endoscopy room and the PI performed the colonoscopy. Patients were randomly assigned to undergo $\mathrm{m}$-WI method colonoscopy with LLP or RLP starting position. Patients with LLP (control group) were in the left lateral position with right hip and knee flexed and left leg straight at the beginning and change the position into supine and at last right lateral position when it was needed. Patients with RLP (treatment group) were in the right lateral position with both hips and knees flexed at the beginning and changed the position into supine and at last left-lateral position when it was needed. When the PI was about to start the single-handed $\mathrm{m}$-WI method of colonoscopy examination, the blinded observer opened the sealed envelope with the code enclosed. A standard colonoscopy was inserted. The patient was asked to change position as needed. Oximetry, cardiac rhythm, and blood pressure were monitored during the examination. The colonoscopy procedure in this study was unblinded because of the different patient starting position. The PI had fewer than 20 cases of RLP colonoscopy experience at the start of this study. A standard white light video colonoscope $(12.8 \mathrm{~mm}$ in diameter) was used in this study. Pauldrach endoscopy water jet pump with $10.4 \mathrm{~mL} / \mathrm{second}$ flow rate was used to infuse water. Water (unwarmed) was infused as needed by the endoscopic water pump through the adaptor on the colonoscope based on the judgment of the endoscopist. The original WI method used infused clean water during insertion and evacuated all of the water during withdrawal. The term modified was used to differentiate the method from the original WI method. Modified-WI method of colonoscopy referred to the episodic but repeated suction applied to straighten the angulated colon so that the scope could be pushed forward. Usual air insufflation and water evacuation were performed during colonoscope withdrawal to facilitate mucosal examination. We did not perform external abdominal compression during colonoscopy examination to maintain similar measure in both groups.

\section{Primary Outcome Variable}

The abdominal discomfort score was the primary outcome of this study. The patient reported level of abdominal discomfort experienced during the colonoscopy examination. The patients punctuated the VAS score line form by themselves, immediately after the end of examination (patient was still on 
the examination bed). The VAS was measured on a linear visual analog scale: $0=$ none, $10=$ most severe.

\section{Secondary Outcome Variables}

The cecal intubation time from the anus, cecal intubation rate, total volume of the infused water, time to pass rectosigmoid, and willingness to repeat the colonoscopy examination were the secondary outcomes. The cecal intubation rate was defined as the proportion of patients with successful insertion of the colonoscope to the cecum with the tip of the colonoscope touching the floor of the cecum with visualisation of the medial cecal wall between the ileocecal valve and/or appendix orifice. The time to pass rectosigmoid was measured from insertion to when the colonoscope length passed the $40 \mathrm{~cm}$ marking on the colonoscope without looping. We also recorded the difficulties during colonoscope insertion, such as looping or needing to change from starting position.
We developed the bowel visualization scale (BVS) (Figure 2) to measure the influence of the suspended fecal matter during colonoscope insertion on cecal intubation rate and time. The suspended fecal matter in the water could make the water-aided colonoscopy examination more difficult compared with the air insufflation method.

\section{Analysis of Data}

Sample size was determined based on our preliminary VAS score study in small number of unsedated m-WI colonoscopy cases which showed that the mean \pm SD of LLP was $3.83 \pm 2.04$ and RLP was 2.67 \pm 1.63 . Mean difference 3.83-$2.67=1.16$. Standard deviation units $0.4 / 3.9=0.01$. The sample size based on the table (two-tailed $\alpha=0.01,80 \%$ power) with $\mathrm{SD}=2.04$, and the mean difference as $\mathrm{SD}$ units $=1.16$ / $2.04=0.57$ (rounded to 0.5 ) is $64 \times 2=128$ with $10 \%$ possible dropout for any reason; sample size was 142 . The analysis

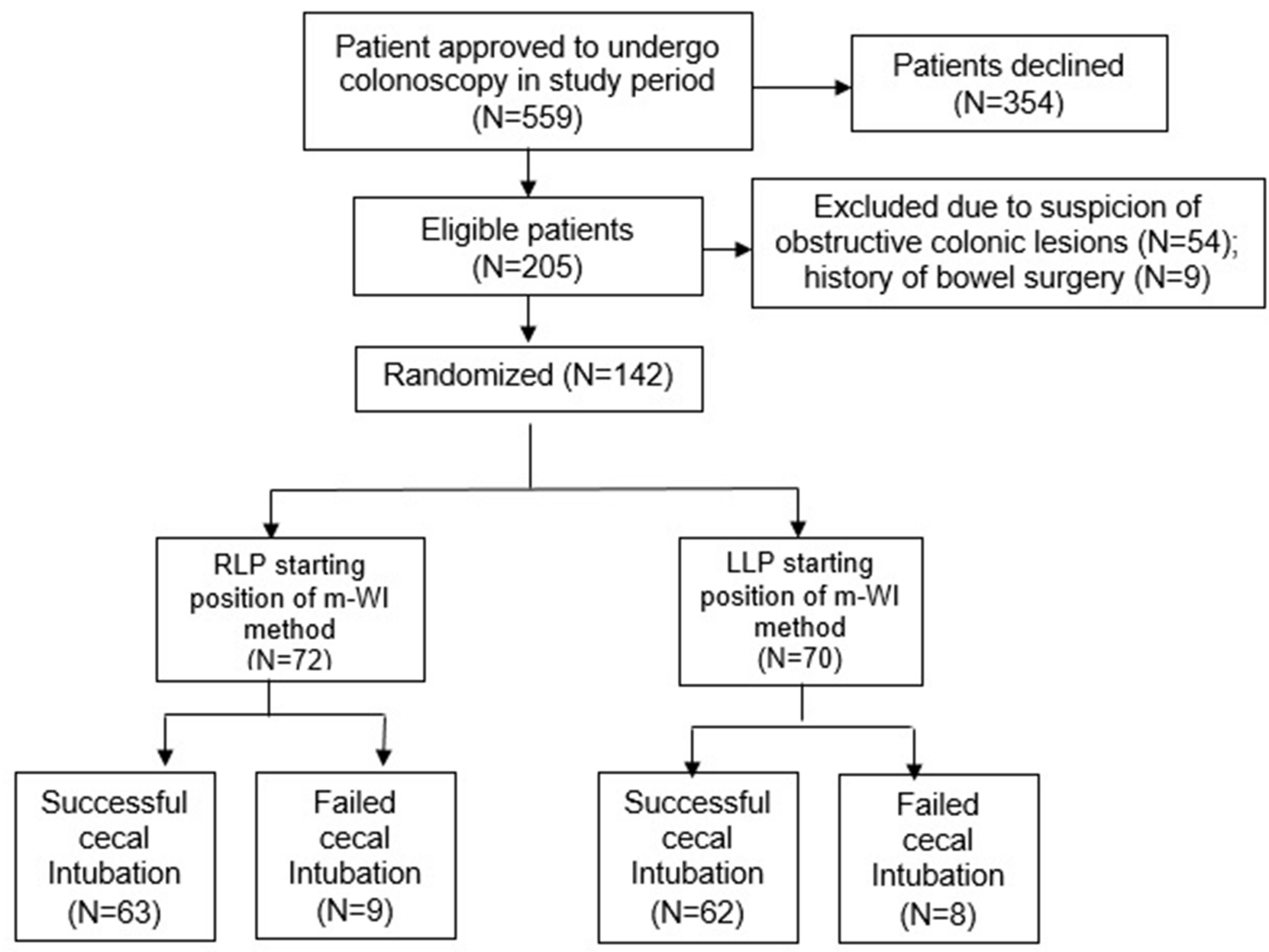

Figure I Flow chart of patient enrollment. 
used IBM SPSS statistical software. Descriptive statistics were used to evaluate the distribution of each variable. Data were presented as frequency counts and percentage of total, mean $\pm \mathrm{SD}$. Chi-squared/Fisher's exact test, the $t$-test were used to evaluate the independent samples, with $p<0.05$ considered to be significant.

\section{Results}

As many as 142 patients were enrolled in this study (Figure 1). Hematochezia was the commonest indication for colonoscopy (Table 1). There were no significant differences in pain score, cecal intubation rate, time to pass rectosigmoid and willingness to repeat between LLP and RLP. The cecal intubation time was nearly significantly ( $p$ value only reached $p=0.054$ ) different between the two groups (Table 2).

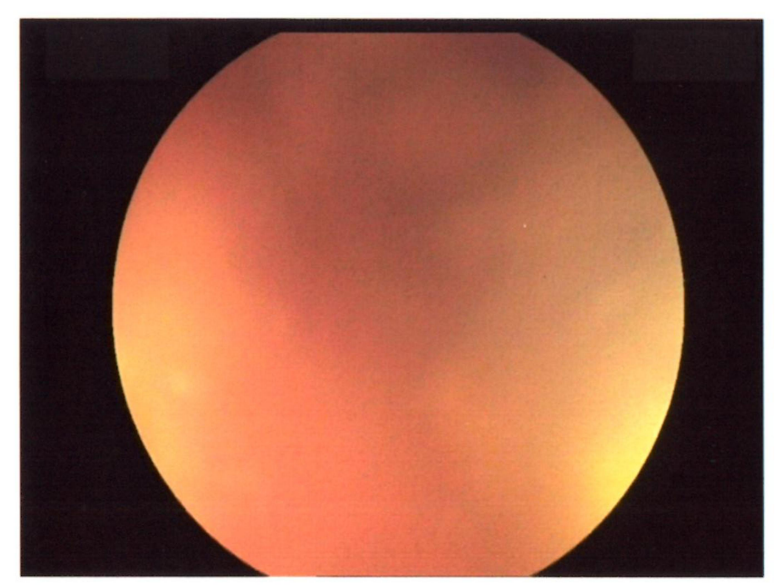

Scale $0=$ totally blurred visualization

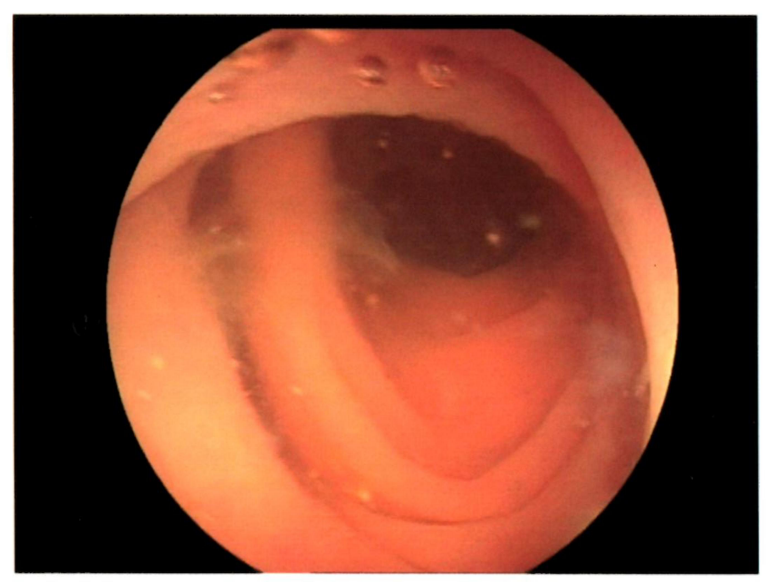

Scale 2= small fecal debris with clear mucosa visualization
The LLP showed shorter cecal intubation time in the constipation group and in BVS- 2 (Table 3). When we combined patients with BVS-2 and BVS-3 the result remained significantly different. We did not find any patient with BVS-0 in this study. No patient in the failure group was due to suspended fecal matter blocking the view. During colonoscopy fixed position was found in 10 (15.8\%) RLP patients and $7(11.3 \%)$ LLP patients ( $p=$ $0.60)$; changed only into supine position: 48 (96\%) patients in RLP and 38 (70.4\%) patients in LLP $(p=0.084) ; 3(6 \%)$ RLP patients changed into supine then left lateral decubitus (contralateral position) and 17 (31.5\%) LLP patients changed into supine then right lateral decubitus (contralateral position) with $p=0.001$. No adverse event was found during the study.

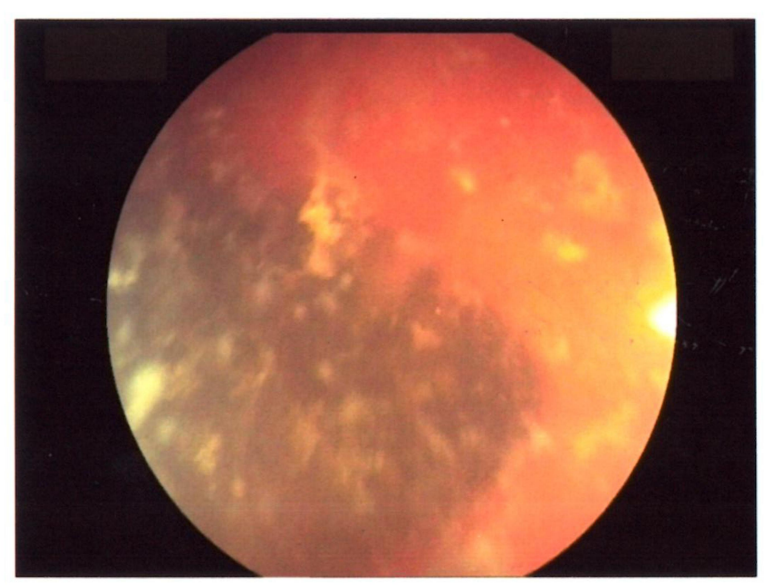

Scale $1=$ blurred lumen visualization

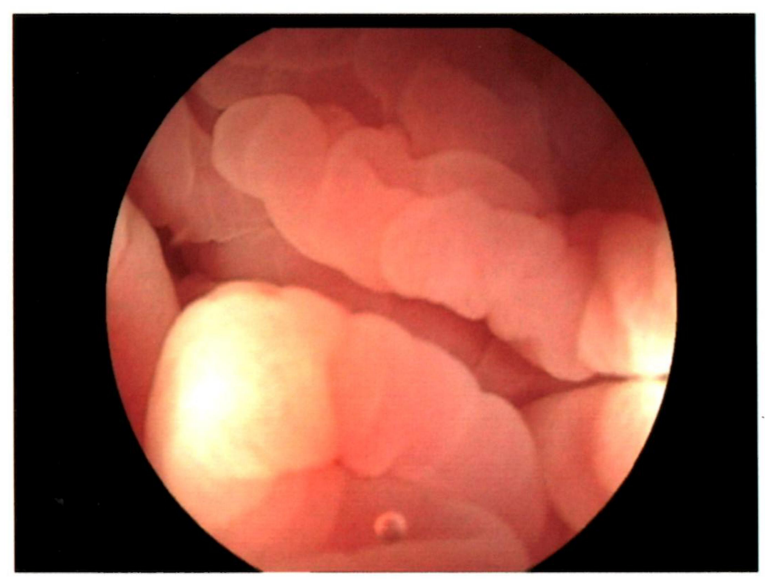

$3=$ Clear

Figure 2 The proposed colonic bowel visualization scale that was observed predominantly during m-WI colonoscopy examination in this study (Images source: Originally from Dr Sardjito General Hospital Endoscopy Reporting System). 
Table I Demographic and Basic Characteristics Variables

\begin{tabular}{|l|l|l|l|}
\hline Variables & Right-lateral Starting Position & Left-lateral Starting Position & $\boldsymbol{p}$-value \\
\hline $\mathrm{n}$ & 72 & 70 & \\
\hline Gender (male/female) & $38 / 34$ & $42 / 28$ & 0.40 \\
Age (years) & $48.8 \pm 14.7$ & $48.3 \pm 14.7$ & 0.82 \\
\hline Colonoscopy Indications & & & \\
Chronic diarrhea & 17 & 13 & 0.54 \\
Chronic lower abdominal discomfort & 10 & 5 & 0.28 \\
Chronic constipation & 10 & 10 & 1.00 \\
Hematochezia & 20 & 29 & 0.11 \\
Others & 15 & 13 & 0.83 \\
\hline
\end{tabular}

\section{Discussion}

This study showed result that was different from the previous sedated colonoscopy study comparing RLP and LLP with air insufflation method. In that study the RLP showed significantly better performance (more comfortable and quicker procedure) than LLP. ${ }^{4}$

Table 2 Effect of RLP and LLP on Measured Parameters

\begin{tabular}{|c|c|c|c|}
\hline \multirow[t]{2}{*}{ Measured Parameters } & \multicolumn{2}{|c|}{ Patient Starting Position in Unsedated m-WI Colonoscopy } & \multirow[t]{2}{*}{$p$-value } \\
\hline & Right-lateral Starting Position & Left-lateral Starting Position & \\
\hline Time to pass rectosigmoid $(\mathrm{min})^{\mathrm{a}}$ & $4.26 \pm 2.67$ & $4.19 \pm 2.30$ & 0.87 \\
\hline Cecal intubation time $(\mathrm{min})^{\mathrm{a}}$ & $13.43 \pm 4.5$ & $\mathrm{II} .7 \pm 5.4$ & 0.054 \\
\hline Cecal intubation rate ${ }^{c}$ & 63 of $72(87.5 \%)$ & 62 of $70(88.6 \%)$ & 1.00 \\
\hline Pain score (VAS I-I0) ${ }^{\mathrm{a}}$ & $4.5 \pm 3.0$ & $4.2 \pm 2.7$ & 0.56 \\
\hline VAS score $<4.4$ (mild pain) ${ }^{c}$ & 32 of $72(44.4 \%)$ & 31 of $70(44.3 \%)$ & 0.92 \\
\hline Willingness to repeat ${ }^{c}$ & 48 of $63(76.2 \%)$ & 46 of $62(74.2 \%)$ & 0.79 \\
\hline Redundancy but successful (n) & 28 & 24 & 0.26 \\
\hline Time to pass rectosigmoid $(\mathrm{min})^{\mathrm{a}}$ & $4.7 \pm 3.2$ & $5.62 \pm 2.80$ & 0.66 \\
\hline Cecal intubation time $(\min )^{\mathrm{a}}$ & $|4.7 \pm 5|$. & $14.0 \pm 5.8$ & \\
\hline Failure due to redundancy $(n)^{c}$ & 8 & 5 & 0.56 \\
\hline Failure due to pain $(n)^{\mathrm{b}}$ & I & 3 & 0.36 \\
\hline Constipation group (n) & 9 & 8 & 0.28 \\
\hline Time to pass rectosigmoid $(\mathrm{min})^{\mathrm{a}}$ & $5.1 \pm 3.6$ & $3.5 \pm 2.0$ & 0.001 \\
\hline Cecal intubation time $(\mathrm{min})^{\mathrm{a}}$ & $16.0 \pm 3.5$ & $8.6 \pm 3.8$ & \\
\hline Non-constipation group $(n)$ & 54 & 54 & 0.93 \\
\hline Time to pass rectosigmoid (min) ${ }^{a}$ & $4.2 \pm 2.6$ & $4.2 \pm 2.2$ & 0.15 \\
\hline Cecal intubation time $(\min )^{a}$ & $13.3 \pm 4.7$ & $11.9 \pm 5.3$ & \\
\hline External abdominal compression & 0 of 72 & 0 of 70 & \\
\hline Patient position change ${ }^{c}$ & 50 of $63(79.4 \%)$ & 54 of $62(87.1 \%)$ & 0.34 \\
\hline Infused water $(\mathrm{mL})^{\mathrm{a}}$ & $592.1 \pm 241.7$ & $577.0 \pm 253.0$ & 0.73 \\
\hline
\end{tabular}

Notes: VAS, visual analog scale ( $I=$ no pain, $10=$ worst pain); mild pain defined as $<4.4 ; 7^{7}$ Student's $t$-test. ${ }^{b}$ Fisher's exact test. ${ }^{\circ}$ Chi-squared test.

Abbreviations: $\mathrm{m}$-WI, modified-water immersion; RLP, right-lateral starting position; LLP, left-lateral starting position. 
Table 3 Effect of Bowel Visualization During m-WI Colonoscopy on Measured Parameters (Based on Figure 2)

\begin{tabular}{|l|l|l|l|}
\hline \multirow{2}{*}{ Measured Parameters } & \multicolumn{2}{|l|}{ Patients Starting Position in Unsedated m-WI Colonoscopy Examination } \\
\cline { 2 - 4 } & Right-lateral Starting Position & Left-lateral Starting Position \\
\hline Cecal intubation rate (n) ${ }^{\mathrm{a}}$ & & & \\
Scale I & 21 of 63 & 23 of 62 & 0.71 \\
Scale 2 & 31 of 63 & 28 of 62 & 0.72 \\
Scale 3 & II of 63 & 11 of 62 & 1.00 \\
Scale 2+Scale 3 & 42 of 63 & 39 of 62 & 0.71 \\
\hline Cecal intubation time (min) & & & $13.5 \pm 6.0$ \\
Scale I & $13.8 \pm 5.1$ & $10.3 \pm 4.2$ & 0.85 \\
Scale 2 & $13.9 \pm 4.6$ & $11.5 \pm 6.1$ & 0.003 \\
Scale 3 & $11.4 \pm 2.5$ & $10.6 \pm 4.8$ & 0.98 \\
Scale 2+Scale 3 & $13.2 \pm 4.3$ & 0.01 \\
\hline
\end{tabular}

Notes: ${ }^{a}$ Chi-squared test. 'btudent's t-test.

Abbreviations: m-WI, modified-water immersion; Scale I, blurred lumen visualization; Scale 2, small fecal debris with clear mucosal visualization; Scale 3, clear; Scale 0, totally blurred visualization was excluded from the study.

The different result may be due to the different characteristic between water and air in the colonoscopy examination. In the air insufflation method with the LLP starting position, the right colon was in high point position so that the insufflated air easily travels there and lengthened the colon making it more difficult to reach the cecum and consequently more painful for the patient. In the air insufflation method with RLP starting position, the right colon in low point position so that the insufflated air did not easily travel there and the colon was not lengthened then it was less difficult and less painful. However, in the m-WI method with LLP starting position, the right colon is in the high point position and the infused water weighed the left colon down enough to straighten the sigmoid, hence the colon was not lengthened and making it less difficult and less painful. In m-WI method with RLP starting position the water did not weigh the left colon down enough to straighten the sigmoid, providing no advantage.

Our proposed BVS-2 group also showed the faster performance of LLP starting position in cannulating the cecum. This BVS-2 was the commonest score we found during the study and was practically not so different from the BVS-3 because the colonic mucosa and the colonic lumen were still visible rather than BVS-1. Most of the BVS-1 and BVS-2 scores in this study were found in unpredictable segments but not continuously during $\mathrm{m}-\mathrm{WI}$ colonoscopy examination. As in our previous studies, ${ }^{3,5}$ we used sodium phosphosoda for bowel preparation and there was no colonoscopy failure related to fecal matter obscuring the luminal view. Colonic redundancy was the main cause of insertion failure and contributed to the low cecal intubation rate in this diagnostic case-based study. The decision not to do external abdominal compression possibly affected this result.

In summary, this was the first randomized controlled trial of RLP vs LLP with unsedated $\mathrm{m}$-WI colonoscopy in diagnostic cases. The limitations of this study were single endoscopist, and the proposed BVS scale status was based on endoscopist judgement during colonoscopy examination that was difficult to standardize it.

\section{Conclusion}

This study showed that the RLP did not improve the pain score and supported the LLP as a better choice in performing $\mathrm{m}$-WI colonoscopy examination and a score of at least BVS-2 was needed to afford the faster cecal intubation time.

\section{Data Sharing Statement}

The authors intend to share individual de-identified participant data consist of patients basic characteristic data and patients colonoscopy examinations results to researchers who want to make collaborative research. This data can be accessed by contacting the corresponding author and will be available within three months from initial request.

\section{Acknowledgments}

Thank you for Sumardjo MD, Grendy Fanery MD, Marselino Ricardo MD, Nuraida Wisudani MD, David Simanjuntak MD, Indria Melianti MD, Ns Rofiah and Ns Lilik Azizah, for their assistance during the study. 


\section{Author Contributions}

All authors contributed to data analysis, drafting or revising the article, have agreed on the journal to which the article will be submitted, gave final approval of the version to be published, and agree to be accountable for all aspects of the work.

\section{Disclosure}

All authors declare that they have no conflicts of interest in this work.

\section{References}

1. Leung FW. Methods of reducing discomfort during colonoscopy. Dig Dis Sci. 2008;53:1462-1467. doi:10.1007/s10620-007-0025-9

2. Leung FW, Harker JO, Jackson G, et al. A proof-of-principle, prospective, randomized, controlled trial demonstrating improved outcomes in scheduled unsedated colonoscopy by the water method. Gastrointestinal Endosc. 2010;72:693-700. doi:10.1016/j.gie.2010.05.020
3. Bayupurnama P, Ratnasari N, Indrarti F, et al. The Water-method colonoscopy in routine unsedated colonoscopy examinations: a randomized controlled trial (RCT) in diagnostic cases in Indonesian patients. $J$ Interv Gastroenterol. 2013;3:12-17. doi:10.7178/jig.101

4. Vergis N, McGrath AK, Stoddart CH, et al. A randomized controlled trial of right- versus left-sided starting position in colonoscopy. $\mathrm{Am}$ J Gastroenterol. 2015;110:1576-1581. doi:10.1038/ajg.2015.298

5. Bayupurnama P, Ratnasari N, Indrarti F, et al. Endoscope-connected water pump with high flow rates improves the unsedated colonoscopy performance by water immersion method. Clin Exp Gastroenterol. 2018;11:13-18. doi:10.2147/CEG.S152669

6. Leung JW, Do LD, Siao-Selera RM, et al. Retrospective analysis showing the water method increased adenoma detection rate- a hypothesis-generating observation. $J$ Interv Gastroenterol. 2011;1:3-7. doi:10.4161/jig.1.1.14585

7. Jensen MP, Chen C, Brugger AM. Interpretation of visual analog scale ratings and change scores: a reanalysis of two clinical trials of postoperative pain. J Pain. 2003;4:407-414. doi:10.1016/S15265900(03)00716-8

\section{Publish your work in this journal}

Clinical and Experimental Gastroenterology is an international, peerreviewed, open access, online journal publishing original research, reports, editorials, reviews and commentaries on all aspects of gastroenterology in the clinic and laboratory. This journal is indexed on American Chemical Society's Chemical Abstracts Service (CAS)
The manuscript management system is completely online and includes a very quick and fair peer-review system, which is all easy to use. Visit http://www.dovepress.com/testimonials.php to read real quotes from published authors. 